\title{
Erratum to: EURO-CORDEX: new high-resolution climate change projections for European impact research
}

\author{
Daniela Jacob · Juliane Petersen · Bastian Eggert - Antoinette Alias • Ole Bøssing Christensen • \\ Laurens M. Bouwer - Alain Braun · Augustin Colette • Michel Déqué • Goran Georgievski • \\ Elena Georgopoulou • Andreas Gobiet · Laurent Menut • Grigory Nikulin • Andreas Haensler • \\ Nils Hempelmann · Colin Jones · Klaus Keuler · Sari Kovats • Nico Kröner • Sven Kotlarski • \\ Arne Kriegsmann - Eric Martin · Erik van Meijgaard • Christopher Moseley • Susanne Pfeifer • \\ Swantje Preuschmann - Christine Radermacher - Kai Radtke - Diana Rechid - Mark Rounsevell • \\ Patrick Samuelsson - Samuel Somot · Jean-Francois Soussana - Claas Teichmann - Riccardo Valentini • \\ Robert Vautard $\cdot$ Björn Weber $\cdot$ Pascal Yiou
}

Published online: 12 March 2014

(C) Springer-Verlag Berlin Heidelberg 2014

\section{Erratum to: Reg Environ Change DOI 10.1007/s10113-013-0499-2}

The author would like to correct the errors in the publication of the original article. The corrected details are given below for your reading.

In result section, third sentence of the fourth paragraph should read as:

The online version of the original article can be found under doi:10.1007/s10113-013-0499-2.

D. Jacob $(\bowtie) \cdot$ J. Petersen · B. Eggert · A. Haensler .

N. Hempelmann - A. Kriegsmann - C. Moseley - S. Pfeifer ·

S. Preuschmann - D. Rechid . C. Teichmann · B. Weber

Climate Service Center (CSC), Helmholtz-Zentrum Geesthacht,

Fischertwiete 1, 20095 Hamburg, Germany

e-mail: daniela.jacob@hzg.de

D. Jacob $\cdot$ J. Petersen $\cdot$ C. Moseley $\cdot$ C. Radermacher

D. Rechid $\cdot$ C. Teichmann

Max Planck Institute for Meteorology (MPIM), Bundesstr. 53,

20146 Hamburg, Germany

A. Alias · A. Braun - M. Déqué · E. Martin - S. Somot Météo-France/CNRS, Centre National de Recherches Météorologiques (CNRM-GAME), 42, Avenue Gaspard

Coriolis, 31057 Toulouse Cedex 1, France

O. B. Christensen

Danish Climate Centre, Danish Meteorological Institute (DMI), Lyngbyvej 100, 2100 Copenhagen, Denmark

L. M. Bouwer

Institute for Environmental Studies, Vrije Universiteit, De Boelelaan 1087, 1081 HV Amsterdam, The Netherlands
"The zone between regions in which precipitation increases in the north and decreases in the south shifts northwards in summer and southwards in winter"

L. M. Bouwer

Deltares, PO Box 177, 2600 MH Delft, The Netherlands

A. Colette

Institut National de l'Environnement Industriel et des Risques

(INERIS), 60550 Verneuil-en-Halatte, France

G. Georgievski · K. Keuler · K. Radtke

Environmental Meteorology, Brandenburg University of

Technology, Burger Chaussee 2, 03013 Cottbus, Germany

\section{E. Georgopoulou}

Institute for Environmental Research and Sustainable

Development (IERSD), National Observatory of Athens,

11810 Thissio, Greece

A. Gobiet

Wegener Center for Climate and Global Change and Institute for Geophysics, Astrophysics, and Meteorology, University of Graz, Brandhofgasse 5, 8010 Graz, Austria

L. Menut

Laboratoire de Météorologie Dynamique (IPSL), Ecole

Polytechnique, 91128 Palaiseau Cedex, France 
The ranges in Table 3 should be:

Cold spell duration index, Max, Continental, RCP8.5 from -6 to -8 .

Annual total precipitation, Min, Southern, RCP4.5 from -11 to 2 .

Annual total precipitation, Max, Southern, RCP4.5 from 2 to -11 .

The correct Table 3 is given in the following page.

G. Nikulin · C. Jones · P. Samuelsson Swedish Meteorological and Hydrological Institute (SMHI), Folkborgsvägen 17, 60176 Norrköping, Sweden

\section{S. Kovats}

London School of Hygiene and Tropical Medicine,

15-17 Tavistock Place, London WC1H 9 SH, UK

\section{N. Kröner · S. Kotlarski}

Institute for Atmospheric and Climate Science, ETH Zurich,

Universitätstrasse 16, 8092 Zurich, Switzerland

E. van Meijgaard

Royal Netherlands Meteorological Institute (KNMI),

Wilhelminalaan 10, 3732 GK De Bilt, The Netherlands

M. Rounsevell

David Kinloch Michie Chair of Rural Economy \&

Environmental Sustainability, Institute of Geography \& the

Lived Environment, School of GeoSciences, The University of

Edinburgh, Drummond Street, Edinburgh EH8 9XP, UK
J.-F. Soussana

INRA, UR874, Grassland Ecosystems Research (UREP),

Clermont-Ferrand, France

R. Valentini

Department of Forest Science and Environment,

University of Tuscia, Viterbo, Italy

R. Valentini

Euro-Mediterranean Center for Climate Change, Via De Lellis, 01100 Viterbo, Italy

R. Vautard · P. Yiou

Laboratoire des Sciences du Climat et de l'Environnement, IPSL, CEA/CNRS/UVSQ, Gif sur Yvette, France 


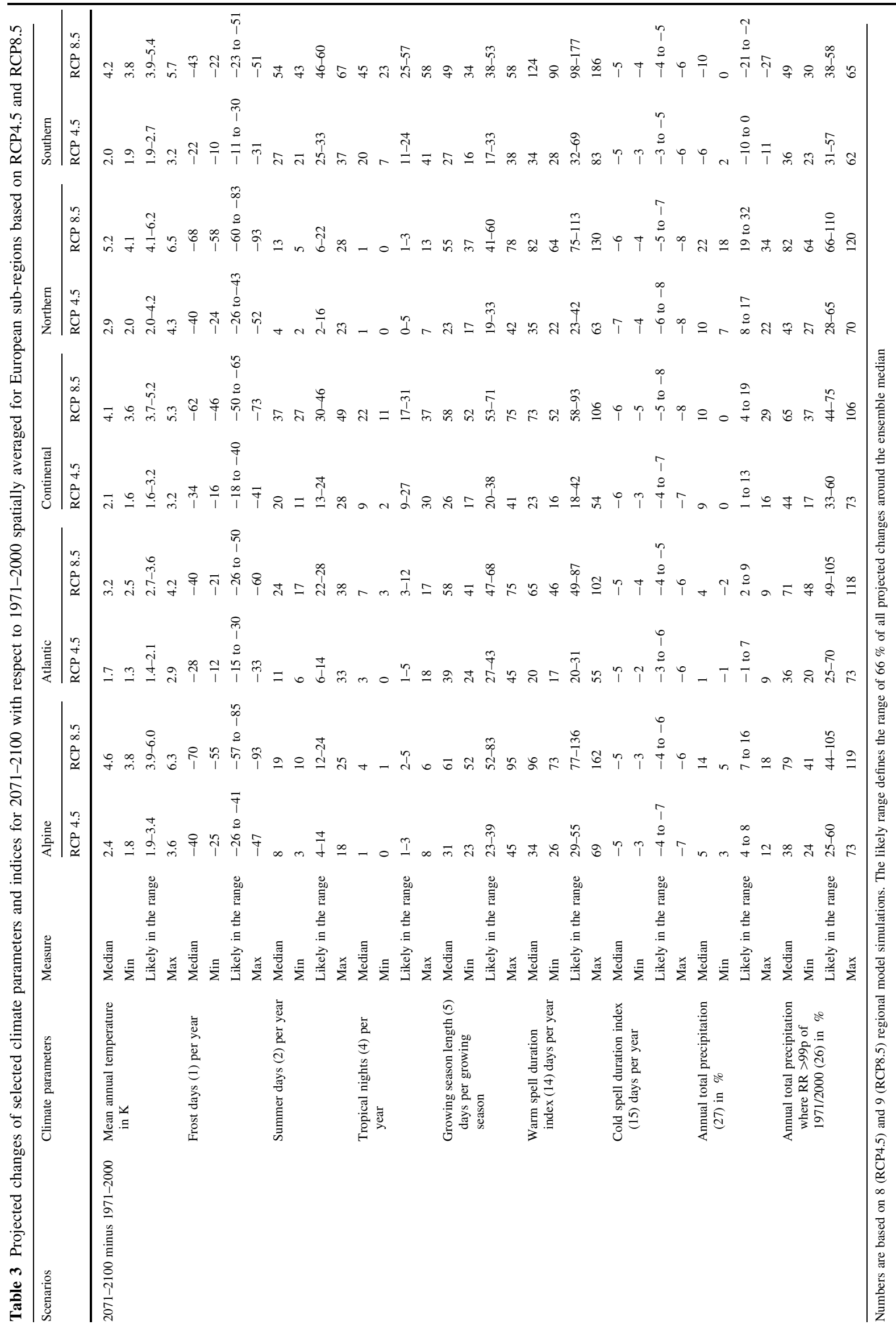

